\title{
High Efficacy of Praziquantel in Schistosoma haematobium-Infected Children in Taraba State, Northeast Nigeria A follow-up study
}

"Robert S. Houmsou, ${ }^{1}$ Binga E. Wama, ${ }^{1}$ Hemen Agere,${ }^{2}$ John A. Uniga, ${ }^{3}$ Elizabeth U. Amuta, ${ }^{4}$ Santaya L. Kela ${ }^{5}$

$$
\begin{aligned}
& \text { فعالية عالية لدواء برازيكوانتيل في أطفال مصابين بطفيل البلهارسية } \\
& \text { الدموية في ولاية ترابا بنيجيريا } \\
& \text { دراسة متابعة }
\end{aligned}
$$

روبرت همسو، بنجا واما، هيمن أقري، جون يونقا، أليزابيث أموتا، سانتايا كيلا

ABSTRACT: Objectives: This study aimed to assess the efficacy of praziquantel in reducing urinary schistosomiasis prevalence, parasite burden and morbidity rates among a previously reported sample of Schistosoma haematobiuminfected children. In addition, predisposing factors for reinfection one year post-treatment were also determined. Methods: This prospective follow-up study was conducted between March 2014 and February 2015 among 675 previously reported children with urinary schistosomiasis in the Murbai and Surbai communities of Ardo Kola, Taraba State, Nigeria. A single dose of $40 \mathrm{mg} / \mathrm{kg}$ of praziquantel was administered to each infected child, with a second dose administered one month later if necessary. The number of S. haematobium eggs in urine samples was calculated at baseline and post-treatment. Results: At four weeks post-treatment, the overall cure rate was $98.1 \%$. Among children with low and heavy parasite burdens at baseline, egg reduction rates (ERRs) were 100\% and 96.5\%, respectively. The vast majority of children with microhaematuria (98.7\%) and proteinuria (98.6\%) at baseline were cured at follow-up. Following a second dose, the ERR, overall and morbidity cure rates increased to $100 \%$. At one year post-treatment, 272 infected children (40.3\%) were re-assessed; of these, 51 children (18.8\%) were reinfected. Close proximity to bodies of water (odds ratio $[\mathrm{OR}]=1.23$, 95\% confidence interval [CI]: 0.998-1.530; $P=0.05$ ) and fishing $(\mathrm{OR}=2.23,95 \%$ CI: 0.828-6.040; $P=0.01)$ were significant factors that predisposed children to reinfection. Conclusion: A moderate rate of reinfection was noted. Governmental and nongovernmental organisations in Nigeria should collaborate on mass treatment and health education campaigns to reduce the incidence of urinary schistosomiasis reinfections.

Keywords: Urinary Schistosomiasis; Praziquantel; Treatment Outcome; Follow-Up Study; Nigeria.

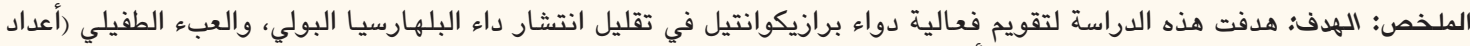

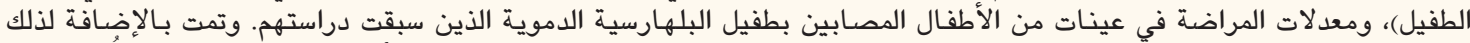

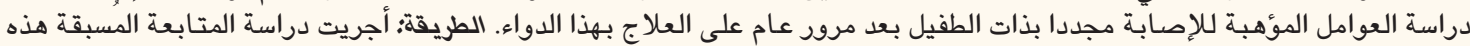

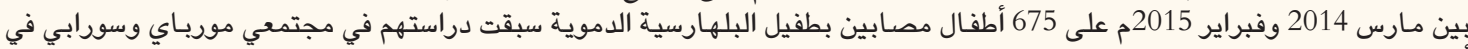

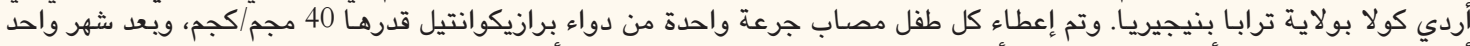

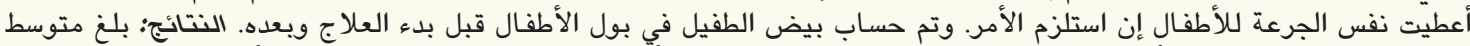

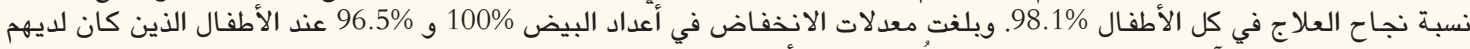

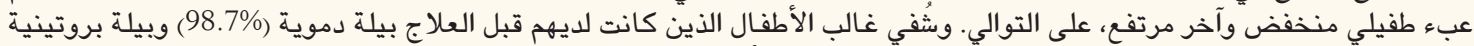

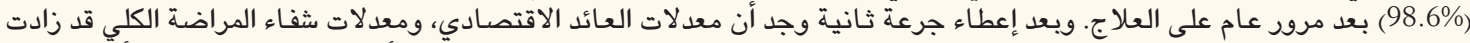

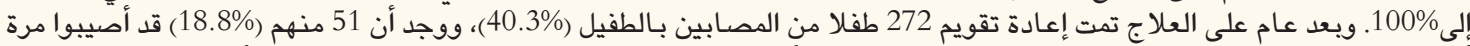

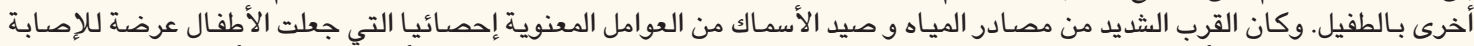

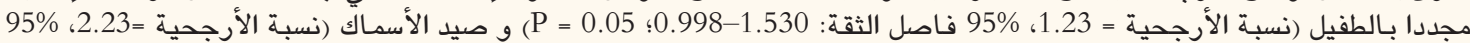

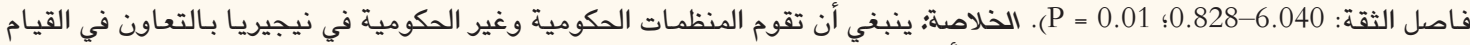
بحملات للعلاج الجماعي والتثقيف الصحي من أجل تقليل حدوث عودة الفئ عدوى البلهارسيا البولية.

الكلمات المفتاحية: البلهارسيا البولية؛ برازيكوانتيل؛ نتائج العلاج؛ دراسة متابعة؛ نيجيريا. 


\section{Advances in KNOWLEdge}

This follow-up study found that a single dose of praziquantel was highly effective in treating urinary schistosomiasis among a previously reported sample of infected children in Nigeria.

However, proximity to bodies of water and participation in water-related activities such as fishing were significant factors predisposing children to reinfection one year after treatment.

\section{Application to Patient Care}

The administration of a single dose of $40 \mathrm{mg} / \mathrm{kg}$ of praziquantel is recommended to cure children with urinary schistosomiasis of the disease, as well as related morbidities such as microhaematuria and proteinuria.

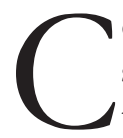
OMMONLY KNOWN AS BILHARZIA, SCHISTOsomiasis is a water-related parasitic disease transmitted to humans transcutaneously by matured furcocercariae that multiply asexually within freshwater snails of the Planorbidae family. ${ }^{1}$ In subSaharan Africa, Nigeria carries the highest burden of the disease, with an estimated 103.9 million people at risk of infection and 29 million individuals infected. ${ }^{2}$ In Nigeria, the disease is predominantly caused by two species of schistosomes-Schistosoma haematobium and S. mansoni-which overlap in most endemic areas, although $S$. intercalatum has also been reported. ${ }^{3,4}$ For the most part, people living in rural areas of Nigeria are most often infected with $S$. haematobium., ${ }^{5,6}$ The disease is known to cause haematuria, proteinuria, leukocyturia, dysuria and painful urination; it has also been reported to have significant adverse effects on child development and to affect productivity in infected adults. $^{1,7-9}$

In schistosomiasis-endemic areas, the World Health Organization (WHO) recommends the administration of a single dose of praziquantel to affected individuals during mass deworming campaigns. ${ }^{10}$ Previous studies have also shown that this drug remains the safest and most effective treatment for all forms of schistosomiasis. ${ }^{11,12}$ While poor cure rates with a single dose of praziquantel have been reported in $S$. mansoni-endemic areas, better cure and egg reduction rates (ERRs) have been reported in S. haematobium-endemic areas..$^{12-15}$ However, in spite of the dramatic increase in the availability and distribution of praziquantel over the last decade, less than 40 million out of 260 million infected individuals worldwide in 2013 received treatment. ${ }^{15}$ Moreover, in Nigeria, little has been done to reduce the prevalence and intensity of urinary schistosomiasis infections in endemic communities. Although a national schistosomiasis map was created to promote interventions and strategies to combat the disease, only $4 \%$ of those in need of the drug have been treated so far. ${ }^{16,17}$ In Nigeria, previous studies have reported schistosomiasis to be endemic in Taraba State, with specific prevalence rates varying between communities. ${ }^{16,18}$ Despite this, to the best of the authors' knowledge, there has been no mass distribution of praziquantel to date in this region. ${ }^{18}$
The Murbai and Surbai villages of the Ardo Kola Local Government Area (LGA) of Taraba State are hyperendemic areas for S. haematobium. ${ }^{18}$ Most residents are subsistence farmers who also engage in fishing and trading. The area has a tropical climate and a mixture of savannah vegetation. ${ }^{18}$ Ponds, streams and rivers traverse both communities, with the majority of inhabitants dependent on these bodies of water for their daily activities. Previously, an epidemiological study was conducted among 1,153 children in the Murbai and Surbai communities, of which 675 (58.5\%) were found to be infected with $S$. haematobium; fishing, rice farming and dry season farming using irrigation were identified as significant risk factors for infection. ${ }^{18}$ However, only baseline prevalence and parasite burden was determined during the course of the initial study. Therefore, the current followup study aimed to assess the efficacy of a single dose of praziquantel in reducing prevalence, parasite burden and morbidity rates among the same sample of infected children. In addition, factors predisposing children to reinfection one year after treatment were evaluated.

\section{Methods}

This prospective follow-up study was conducted between March 2014 and February 2015 and included a previously reported sample of 675 children with urinary schistosomiasis infections in the Murbai and Surbai communities. ${ }^{18}$ All infected children were treated with a single dose of $40 \mathrm{mg} / \mathrm{kg}$ of praziquantel administered by two qualified nurses according to WHO protocols. ${ }^{19}$ The treated children were followed up for four weeks, after which they were re-examined to ascertain the presence of S. haematobium eggs in their urine. Those children who still excreted S. haematobium eggs at this time were given a second dose of praziquantel and followed up again for two more weeks before being reexamined. After 12 months, all children who had been treated with either one or two doses of praziquantel were re-assessed for infection. Unfortunately, a number of the children's families had left the villages during this time, frequently for agricultural purposes or so that the children could attend secondary schools in neighbouring villages. These children were therefore lost to further follow-up [Figure 1]. 


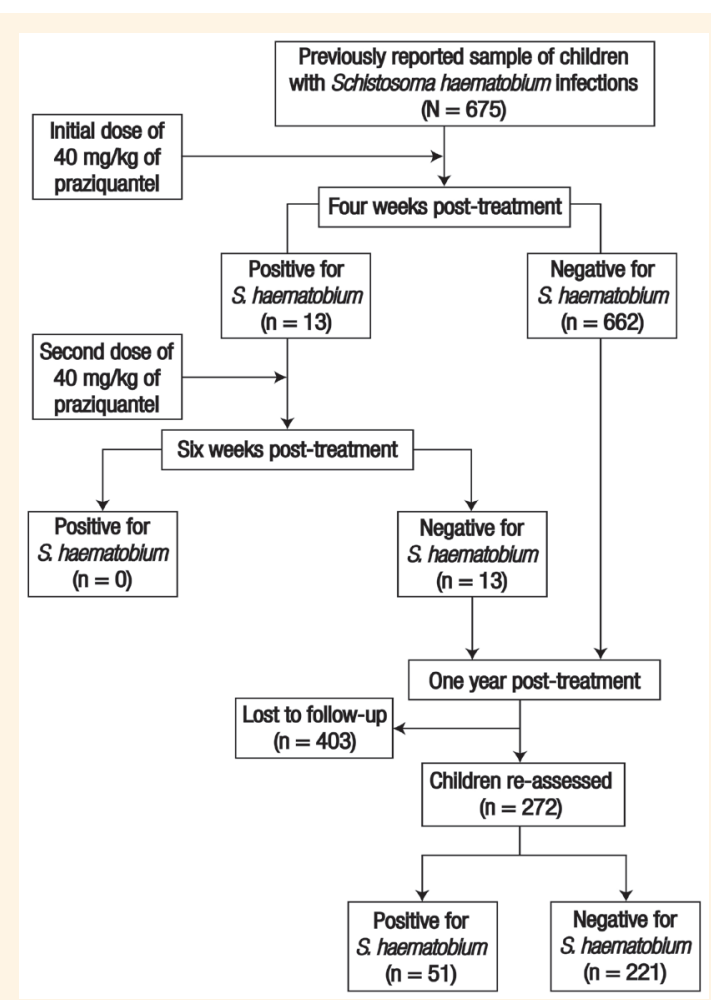

Figure 1: Diagram of study design showing the number of infected children at baseline, follow-up and one year post-treatment among a sample of previously reported children with Schistosoma haematobium infections in Taraba State, Nigeria $(\mathrm{N}=675) .{ }^{18}$

Urine samples of $20 \mathrm{~mL}$ each were collected from the children at baseline and each subsequent follow-up appointment in labelled universal bottles. All samples were collected between 10 AM and 2 PM and were immediately tested for microhaematuria and proteinuria using reagent strips (Medi-Test Combi $9^{\circledR}$, MacheryNagel GmbH Co., Düren, Germany), as per the manufacturer's instructions. All tested urine samples were kept in an ice-packed cooler and transported to the laboratory within 30 minutes. The urine samples were filtered using a $10 \mathrm{~mL}$ syringe with a Swinnex ${ }^{\circledR}$ polypropylene filter holder of $13 \mathrm{~mm}$ in diameter and polycarbonate membrane filters of $12 \mu \mathrm{m}$ porosity (Sterlitech Corp., Kent, Washington, USA). Positive samples were classified as having either a low (1-49 eggs/10 mL of urine) or high (>50 eggs/10 mL of urine) parasite burden. Cure rates and ERRs were calculated using the following formulae, where $\mathrm{P}$ is prevalence and MEC is the arithmetic mean egg count per $10 \mathrm{~mL}$ of urine: ${ }^{20}$

$$
\begin{gathered}
\text { Cure rate }=\frac{\text { P before treatment }-P \text { after treatment }}{\text { P before treatment }} \times 100 \\
E R R=\frac{1-M E C \text { after treatment at baseline }}{M E C \text { before treatment }} \times 100
\end{gathered}
$$

Data were entered into an Excel spreadsheet, Version 2010 (Microsoft Inc., Redmond, Washington, USA), before being exported for analysis to the Statistical Package for the Social Sciences (SPSS), Version 23 (IBM Corp., Armonk, New York, USA). Chi-squared and ttests were used to compare the prevalence of infection and parasite burden according to age and gender and to compare the mean number of eggs between those with low and heavy parasite burdens. A logistic regression analysis using odds ratios (ORs) and 95\% confidence intervals (CIs) was used to determine the relationship between reinfection and risk factors. The statistical level of significance was set at $P \leq 0.05$.

Ethical permission to conduct this study was obtained from the Health Department of the Ardo Kola LGA (\#HD/AIK/16/003). Thereafter, the Health Department communicated with the heads of the Murbai and Surbai communities to inform children and their parents of the study protocols. The parents or guardians of all children enrolled in the study provided informed consent prior to their participation.

\section{Results}

This follow-up study included 675 previously reported children infected with S. haematobium prior to praziquantel treatment. As previously described, males were significantly more likely to be infected than females (71.2\% versus 43.7\%; $\left.X^{2}=89.1 ; P<0.01\right) .{ }^{18}$ Children aged 6-10 years and $11-15$ years were also significantly more likely to be infected $(78.7 \%$ and $73 \%$, respectively; $\left.X^{2}=360.9 ; P<0.01\right)$. A low parasite burden was significantly more frequent in comparison to a heavy parasite burden $\left(62.5 \%\right.$ versus $37.5 \%$; $\left.\chi^{2}=97 ; P<0.01\right){ }^{18}$ According to gender, females more frequently had a low parasite burden than males $(70.1 \%$ versus $58.6 \%$; $\left.X^{2}=96.9 ; P<0.01\right)$. Children aged $1-5$ and $11-15$ years old frequently had a low parasite burden $(85.7 \%$ and $55.7 \%$, respectively). ${ }^{18}$

Table 1 presents the schistosomiasis parasite burden and morbidity rates of the children at baseline. The mean number of eggs was $31.1 \pm 7.9$ eggs $/ 10 \mathrm{~mL}$ of urine among children with a low parasite burden and $86.5 \pm 12.1$ eggs $/ 10 \mathrm{~mL}$ of urine among those with a heavy parasite burden. In terms of morbidities, males had a significantly higher proportion of both microhaematuria $\left(61.5 \%\right.$ versus $\left.42.9 \% ; X^{2}=157.8 ; P<0.01\right)$ and proteinuria (49.1\% versus $36.8 \% ; X^{2}=107.9 ; P<0.01$ ) than their female counterparts. Children aged 6-10 and 11-15 years old had the highest proportion of both microhaematuria (61.7\% and $48.3 \%$, respectively; $\left.X^{2}=177.7 ; P<0.01\right)$ and proteinuria (44\% and 50\%, respectively; $\chi^{2}=86.2 ; P<0.01$ ), compared to the $1-5$-year-olds. 
Table 1: Schistosomiasis parasite burden and morbidities at baseline among Schistosoma haematobium-infected children in Taraba State, Nigeria $(\mathrm{N}=675)^{*}$

\begin{tabular}{|c|c|c|c|c|c|c|c|c|}
\hline \multirow[t]{2}{*}{ Variable } & \multicolumn{3}{|c|}{ n (\%) } & \multirow[t]{2}{*}{$P$ value } & \multicolumn{3}{|c|}{ Age group in years, $\mathbf{n}(\%)$} & \multirow[t]{2}{*}{$P$ value } \\
\hline & Total & $\begin{array}{c}\text { Male } \\
(n=444)\end{array}$ & $\begin{array}{l}\text { Female } \\
(\mathrm{n}=231)\end{array}$ & & $\begin{array}{c}1-5 \\
(n=63)\end{array}$ & $\begin{array}{c}6-10 \\
(n=436)\end{array}$ & $\begin{array}{c}11-15 \\
(n=176)\end{array}$ & \\
\hline \multicolumn{9}{|l|}{ Parasite burden $^{\dagger}$} \\
\hline Low & $422(62.5)$ & $260(58.6)$ & $162(70.1)$ & $<0.01$ & $54(85.7)$ & $270(61.9)$ & $98(55.7)$ & $<0.01$ \\
\hline High & $253(37.5)$ & $184(41.4)$ & $69(29.9)$ & $<0.01$ & $9(14.3)$ & $166(38.1)$ & $78(44.3)$ & $<0.01$ \\
\hline $\begin{array}{l}\text { Mean eggs } / 10 \mathrm{~mL} \\
\text { of urine } \pm \mathrm{SD}\end{array}$ & $86.5 \pm 12.1$ & $88.3 \pm 11.3$ & $77.1 \pm 9.4$ & & $75.3 \pm 6.2$ & $98.6 \pm 8.7$ & $84.4 \pm 9.4$ & \\
\hline Proteinuria & $303(44.9)$ & $218(49.1)$ & $85(36.8)$ & $<0.01$ & $23(36.5)$ & $192(44)$ & $88(50)$ & $<0.01$ \\
\hline
\end{tabular}

SD = standard deviation

"Some data previously reported in: Houmsou RS, Agere H, Wama BE, Bingbeng JB, Amuta EU, Kela SL. Urinary schistosomiasis among children in Murbai and Surbai communities of Ardo-Kola Local Government Area, Taraba State, Nigeria. ${ }^{18}{ }^{+}$Parasite burden was classified as either low (1-49 eggs/10 $\mathrm{mL}$ of urine) or high (>50 eggs/10 $\mathrm{mL}$ of urine).

Table 2: Schistosomiasis infections, parasite burden and morbidities at four weeks post-praziquantel treatment among Schistosoma haematobium-infected children in Taraba State, Nigeria $(\mathrm{N}=675)$

\begin{tabular}{|c|c|c|c|c|c|c|c|c|}
\hline \multirow[t]{2}{*}{ Variable } & \multicolumn{3}{|c|}{ n (\%) } & \multirow[t]{2}{*}{$P$ value } & \multicolumn{3}{|c|}{ Age group in years, $\mathbf{n}(\%)$} & \multirow[t]{2}{*}{$P$ value } \\
\hline & Total & $\begin{array}{c}\text { Male } \\
(\mathrm{n}=444)\end{array}$ & $\begin{array}{c}\text { Female } \\
(\mathrm{n}=231)\end{array}$ & & $\begin{array}{c}1-5 \\
(n=63)\end{array}$ & $\begin{array}{c}6-10 \\
(n=436)\end{array}$ & $\begin{array}{c}11-15 \\
(\mathrm{n}=176)\end{array}$ & \\
\hline Infections & $13(1.9)$ & $12(2.7)$ & $1(0.4)$ & $<0.01$ & $0(0)$ & $6(1.4)$ & $7(4)$ & $<0.01$ \\
\hline $\begin{array}{l}\text { Overall cure } \\
\text { rate, } \%\end{array}$ & 98.1 & 97.3 & 99.6 & - & 100 & 98.6 & 96 & - \\
\hline \multicolumn{9}{|l|}{ Parasite burden* } \\
\hline Low & $13(1.9)^{\dagger}$ & $12(2.7)$ & $1(0.4)$ & $<0.01$ & $0(0.0)$ & $6(1.4)$ & $7(3.9)$ & $<0.01$ \\
\hline $\begin{array}{l}\text { Mean eggs/ } 10 \\
\mathrm{~mL} \text { of urine } \pm \mathrm{SD}\end{array}$ & $7.1 \pm 1.1$ & $7 \pm 0.2$ & $5 \pm 1.9$ & - & - & $7.0 \pm 1.4$ & $4.1 \pm 2.4$ & - \\
\hline High & $0(0)$ & $0(0)$ & $0(0)$ & - & $0(0)$ & $0(0)$ & $0(0)$ & $<0.01$ \\
\hline $\begin{array}{l}\text { Mean eggs/ } 10 \\
\mathrm{~mL} \text { of urine } \pm \mathrm{SD}\end{array}$ & - & - & - & - & - & - & - & - \\
\hline \multicolumn{9}{|l|}{ Morbidities } \\
\hline Microhaematuria & $11(1.6)$ & $10(2.3)$ & $1(0.4)$ & $<0.01$ & $0(0)$ & $6(1.4)$ & $5(2.8)$ & $<0.01$ \\
\hline Cure rate, $\%$ & 98.7 & 98 & 99.7 & - & - & 98.7 & 97.5 & - \\
\hline Proteinuria & $10(1.5)$ & $9(2)$ & $1(0.4)$ & $<0.01$ & $0(0)$ & $6(1.4)$ & $4(2.3)$ & $<0.01$ \\
\hline Cure rate, \% & 98.6 & 97.9 & 99.6 & - & - & 98.5 & 97.8 & - \\
\hline
\end{tabular}

SD = standard deviation

*Parasite burden was classified as either low (1-49 eggs/10 mL of urine) or high (>50 eggs/10 mL of urine). ${ }^{\dagger}$ All of the children who relapsed had initially had a high parasite burden at baseline but a low parasite burden four weeks post-treatment.

Table 2 describes the schistosomiasis prevalence, parasite burden and morbidity rates of the children four weeks after the administration of a single dose of praziquantel. The overall cure rate was $98.1 \%$, with only 13 children (1.9\%) requiring a second dose of praziquantel. Children aged $1-5$ years old had a higher cure rate than older children (100\% versus $98.6 \%$ and $96 \%$ for those aged 6-10 years and 11-15 years, respectively). In addition, female children had a higher cure rate than their male counterparts (99.6\% versus 97.3\%). At four weeks post-treatment, the ERR in children with low and heavy parasite burdens was $100 \%$ and $96.5 \%$, respectively. At this time, $5.1 \%$ of the children who had had a heavy parasite burden at baseline had relapsed, although 
Table 3: Schistosomiasis reinfection rates and related risk factors at one year post-praziquantel treatment among Schistosoma haematobium-infected children in Taraba State, Nigeria $(\mathrm{N}=272)$

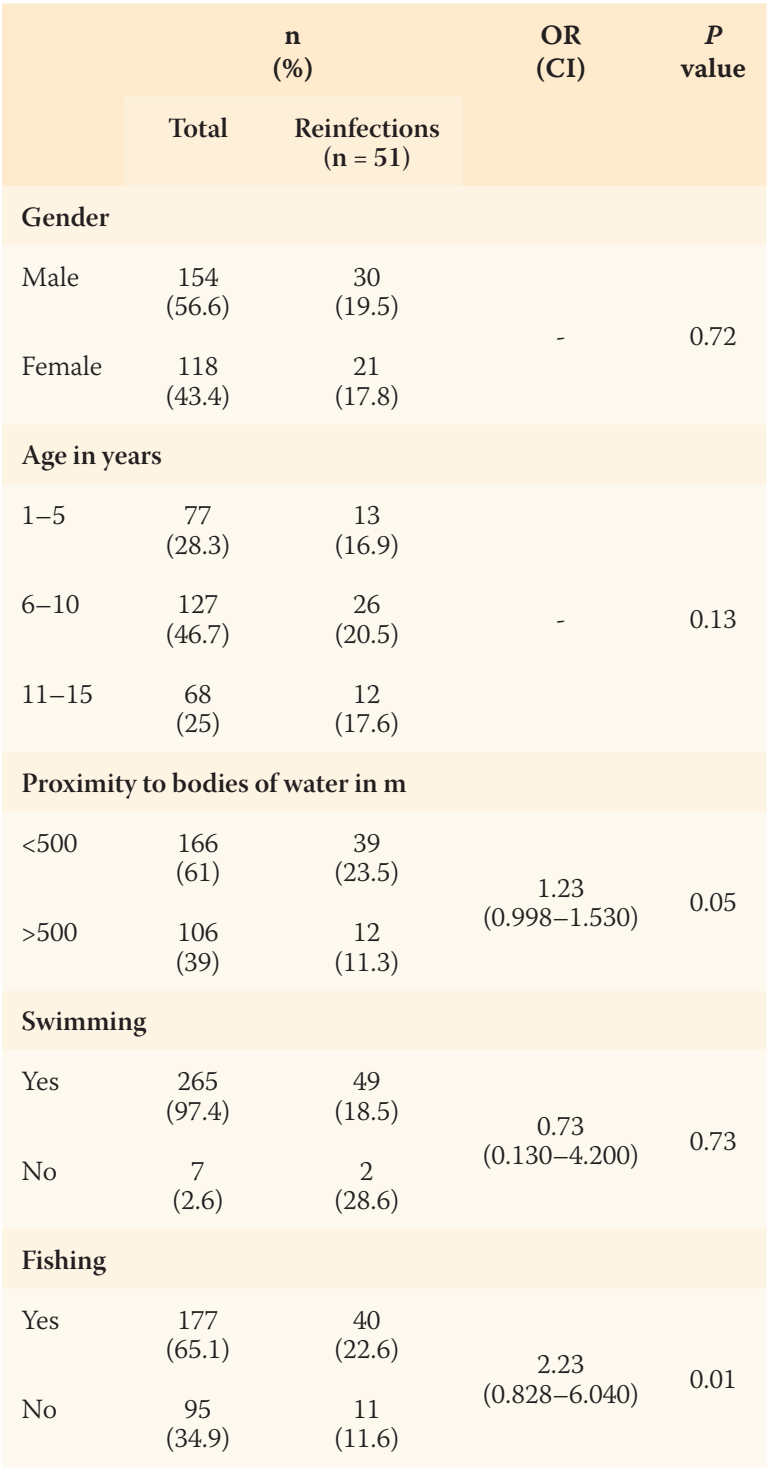

$O R=$ odds ratio; $C I=$ confidence interval.

their parasite burden at follow-up was low (mean: $7.1 \pm 1.1$ eggs/10 mL of urine). In terms of morbidity, cure rates of microhaematuria and proteinuria four weeks post-treatment were $98.7 \%$ and $98.6 \%$, respectively. Among those children who had received a second dose of praziquantel, the ERR and overall and morbidity cure rates were $100 \%$ six weeks post-treatment.

Table 3 shows the prevalence of S. haematobium reinfections and related risk factors one year post-treatment among the 272 children (40.3\%) available for followup. In total, 51 children (18.8\%) were reinfected. However, reinfection rates did not vary significantly by gender $\left(\chi^{2}=0.73 ; P=0.72\right)$ or age $\left(\chi^{2}=1.71 ; P=0.13\right)$. However, close proximity (i.e. within $<500 \mathrm{~m}$ ) to a body of water $(\mathrm{OR}=1.23,95 \% \mathrm{CI}: 0.998-1.530 ; P=0.05)$ and fishing $(\mathrm{OR}=2.23$, 95\% CI: 0.828-6.040; $P=0.01$ ) were significant risk factors for reinfection.

\section{Discussion}

To the best of the authors' knowledge, the current study represents the first longitudinal assessment of the efficacy of a single dose of praziquantel among a sample of previously reported S. haematobium-infected children in Taraba State. ${ }^{18}$ The results of the current study demonstrated the efficacy of praziquantel in reducing the prevalence, burden and morbidity of schistosomiasis infections in two communities with no prior record of mass drug administration. Moreover, observed cure rates at both four (98.1\%) and six (100\%) weeks posttreatment indicated good absorption of praziquantel among infected children who had not previously been exposed to the drug.

Praziquantel remains the drug of choice for treating schistosomiasis, pending development of a more reliable single-dose cure. ${ }^{10}$ The findings of the present study corroborate those of another study from the southern Ivory Coast, which observed similarly high cure rates among infected children at 3-9 weeks post-treatment. ${ }^{20}$ However, in contrast, previous research from Nigeria and Cameroon has indicated much lower cure rates at 3-8 weeks post-treatment $(49.4 \%$ and $39.8 \%$, respectively). ${ }^{21,22}$ This variation in reported cure rates could be the result of several factors, including the frequency of the children's exposure to infested waters, the rate of drug absorption and the extent of drug resistance among the studied populations.

Although no significant gender or age differences were reported in schistosomiasis cure rates at four weeks post-treatment in the current study, females and 1-5year-olds nevertheless had higher cure rates. This finding suggests that praziquantel may be more effective among younger children than older ones, likely due to increased exposure to cercariae-infested water among the latter group due to recreational activities or daily chores. ${ }^{18}$ This may similarly apply to male children; an earlier report observed that male children in Murbai and Surbai spent most of their time swimming and fishing in pools or lakes, as well as more frequently involving themselves in irrigation and rice farming activities. ${ }^{18}$ Lower cure rates among older children and males could also be due to the presence of schistosomula in the bloodstream at the time of treatment, given that praziquantel has proven ineffective against immature Schistosoma parasites. $^{23}$

In the present study, none of the children who required a second dose of praziquantel excreted S. haematobium eggs or showed any signs of morbidity at six weeks post-treatment, suggesting that a second dose of praziquantel may be necessary following poor response to the initial dose. A study conducted in the Niger Republic reported a similar ERR and cure rate after S. haematobium-infected children received a second dose 
of praziquantel three weeks post-treatment. ${ }^{24}$ However, the ERR and cure rate among children in the current study who received either a single or two doses of praziquantel was significantly higher than rates reported from Cameroon, wherein optimal results were only noted at nine weeks post-treatment, with doses of praziquantel administered at three-week intervals. ${ }^{22}$ Moreover, in the present study, most children with a low parasite burden were cured at follow-up, with only a few children with heavy parasite burdens at baseline relapsing at four weeks post-treatment. Similarly, previous research from Mozambique found that a single dose of praziquantel was more effective among children with a low parasite burden in comparison to those with a heavy parasite burden. ${ }^{25}$

In terms of schistosomiasis-related morbidity, the vast majority of children in the present study were cured of microhaematuria and proteinuria at four weeks posttreatment. This indicates that a single dose of praziquantel can potentially reverse the adverse effects of S. haematobium infections. In addition, none of the children requiring a second dose of praziquantel were found to suffer from these morbidities at six weeks post-treatment. Previous studies from Ethiopia and the Ivory Coast have reported low cure rates for microhaematuria and proteinuria at seven and eight weeks post-treatment, respectively. ${ }^{20,26}$ Most studies evaluating the efficacy of praziquantel have assessed morbidity markers of $S$. haematobium over several months and not within weeks. In Kenya, cure rates of $58 \%$ and $46 \%$ were observed at 12 months post-treatment for microhaematuria and proteinuria, respectively. ${ }^{27}$

Unfortunately, a moderate rate of schistosomiasis reinfection was noted among treated children one year post-treatment in the current study. This rate was comparatively higher than reported rates among treated children in Kenya and Sudan. ${ }^{27,28}$ This finding clearly demonstrates the challenges that rural communities such as Murbai and Surbai face with regards to the complete eradication of schistosomiasis. Unfortunately, the lack of piped water in these communities often compels the inhabitants to continue exposing themselves to cercariae-infested bodies of water-for instance, in order to carry out domestic chores or activities such as washing utensils and clothes, bathing, swimming and fishing-thereby re-infecting themselves. As previously reported, close proximity to bodies of water and fishing were identified as major factors that exposed children to infection. ${ }^{18}$ In the current followup study, such factors remained significantly associated with reinfection rates one year post-treatment.
Prompt action is necessary so as to avoid a schistosomiasis epidemic in Taraba State. To this end, a mass praziquantel campaign is recommended, in which all infected individuals are given at least two standard doses of $40 \mathrm{mg} / \mathrm{kg}$ of praziquantel at six-week intervals, in order to curtail the incidence of schistosomiasis reinfections in this region. Furthermore, the effects of praziquantel treatment should be monitored in weeks rather than months. There is also an urgent need to address the problem of high reinfection rates through public health education initiatives to warn local inhabitants of risk factors associated with schistosomiasis reinfections. In addition, the provision of piped water as well as the installation of new or the re-activation of old boreholes or wells within these communities could help to reduce the inhabitants' contact with cercariae-infested water, thereby reducing the incidence of new and recurrent schistosomiasis infections.

The present study is subject to certain limitations. First, an egg viability test was not performed after the initial treatment in order to determine whether the single dose of praziquantel had completely cured the infected children. Second, only $40.3 \%$ of the treated children were still residing within the studied villages one year post-treatment, thus limiting the total number of cases re-assessed.

\section{Conclusion}

Praziquantel was highly effective in curing schistosomiasis among a previously reported sample of $S$. haematobium-infected children in Taraba State. At four weeks post-treatment, both the ERR and overall and morbidity cure rates were extremely high; these increased to 100\% six weeks post-treatment following a second dose of praziquantel. However, there was a moderate rate of reinfection one year post-treatment. Proximity to bodies of water and fishing were significant risk factors for reinfection. The Nigerian Government and other agencies should initiate necessary strategies for treatment and public health education in the region. In particular, the provision of piped water is highly recommended in order to reduce the local inhabitants' contact with cercariae-infested water.

\section{CONFLICT OF INTEREST}

The authors declare no conflicts of interest.

\section{FUNDING}

No funding was received for this study. 


\section{References}

1. Gryseels B, Polman K, Clerinx J, Kestens L. Human schistosomiasis. Lancet 2006; 368:1106-18. doi: 10.1016/S0140-6736(06) 69440-3.

2. Hotez PJ, Kamath A. Neglected tropical diseases in sub-Saharan Africa: Review of their prevalence, distribution, and disease burden. PLoS Negl Trop Dis 2009; 3:e412. doi: 10.1371/journal. pntd.0000412.

3. Arene FO, Ukpeibo ET, Nwanze EA. Studies on schistosomiasis in the Niger Delta: Schistosoma intercalatum in the urban city of Port Harcourt, Nigeria. Public Health 1989; 103:295-301. doi: 10.1016/S0033-3506(89)80043-5.

4. Bassey SE, Orutugu LA. New foci for Schistosoma mansoni and S. intercalatum in Ogbia Local Government Area, Bayelsa State, Nigeria. Biotechnol Res 2016; 2:212-14.

5. Houmsou RS, Panda SM, Elkanah SO, Garba LC, Wama BE, Amuta EU, et al. Cross-sectional study and spatial distribution of schistosomiasis among children in Northeastern Nigeria. Asian Pac J Trop Biomed 2016; 6:477-84. doi: 10.1016/j.apjtb.2016.04.003.

6. Noriode RM, Idowu ET, Otubanjo OA, Mafe MA. Urinary schistosomiasis in school aged children of two rural endemic communities in Edo State, Nigeria. J Infect Public Health 2018; 11:384-8. doi: 10.1016/j.jiph.2017.09.012.

7. Gray DJ, Ross AG, Li YS, McManus DP. Diagnosis and management of schistosomiasis. BMJ 2011; 342:d2651. doi: 10.1136/bmj. d2651.

8. King CH. Parasites and poverty: The case of schistosomiasis. Acta Trop 2010; 113:95-104. doi: 10.1016/j.actatropica.2009.11.012.

9. Mahgoub HM, Mohamed AA, Magzoub M, Gasim GI, Eldein WN, Ahmed AA, et al. Schistosoma mansoni infection as a predictor of severe anaemia in schoolchildren in eastern Sudan. J Helminthol 2010; 84:132-5. doi: 10.1017/S0022149X09990368.

10. WHO Expert Committee. Prevention and control of schistosomiasis and soil-transmitted heliminthiasis. World Health Organ Tech Rep Ser 2002; 912:1-57.

11. Kabatereine NB, Kemijumbi J, Ouma JH, Sturrock RF, Butterworth AE, Madsen $\mathrm{H}$, et al. Efficacy and side effects of praziquantel treatment in a highly endemic Schistosoma mansoni focus at Lake Albert, Uganda. Trans R Soc Trop Med Hyg 2003; 97:599-603.

12. King $\mathrm{CH}$, Muchiri EM, Mungai P, Ouma JH, Kadzo H, Magak P, et al. Randomized comparison of low-dose versus standard-dose praziquantel therapy in treatment of urinary tract morbidity due to Schistosoma haematobium infection. Am J Trop Med Hyg 2002; 66:725-30. doi: 10.4269/ajtmh.2002.66.725.

13. Abu-Elyazeed RR, Youssef FG, Merrell BR, El-Gamal RL, El-Khoby TA, Hassanein YA, et al. Praziquantel in the treatment of Schistosoma mansoni infection: Comparison of 40 and $60 \mathrm{mg} / \mathrm{kg}$ bodyweight regimens. Am J Trop Med Hyg 1997; 56:404-7. doi: 10.4269/ajtmh.1997.56.404.

14. Danso-Appiah A, De Vlas SJ. Interpreting low praziquantel cure rates of Schistosoma mansoni infections in Senegal. Trends Parasitol 2002; 18:125-9. doi: 10.1016/S1471-4922(01)02209-7.

15. World Health Organization. Schistosomiasis: Number of people treated worldwide in 2013. Wkly Epidemiol Rec 2015; 90:25-32.
16. Nigeria Federal Ministry of Health. Report on epidemiological mapping of schistosomiasis and soil transmitted helminthiasis in 19 states and the FCT, Nigeria. From: www.health.gov.ng/ doc/SchistoSTH.pdf Accessed: Nov 2017.

17. World Health Organization. Schistosomiasis: Progress report 2001-2011, strategic plan 2012-2020. From: www.who.int/negle cted_diseases/resources/9789241503174/en/ Accessed: Nov 2017.

18. Houmsou RS, Agere H, Wama BE, Bingbeng JB, Amuta EU, Kela SL. Urinary schistosomiasis among children in Murbai and Surbai communities of Ardo-Kola Local Government Area, Taraba State, Nigeria. J Trop Med 2016; 2016:9831265. doi: 10.11 $55 / 2016 / 9831265$.

19. World Health Organization. Assessing the efficacy of antihelminthic drugs against schistosomiasis and soil-transmitted helminthiases. From: http://apps.who.int/iris/handle/10665/79019 Accessed: Nov 2017

20. Stete K, Krauth SI, Coulibaly JT, Knopp S, Hattendorf J, Müller I, et al. Dynamics of Schistosoma haematobium egg output and associated infection parameters following treatment with praziquantel in school-aged children. Parasit Vectors 2012; 5:298. doi: 10.1186/1756-3305-5-298.

21. Ojurongbe O, Sina-Agbaje OR, Busari A, Okorie PN, Ojurongbe TA, Akindele AA. Efficacy of praziquantel in the treatment of Schistosoma haematobium infection among school-age children in rural communities of Abeokuta, Nigeria. Infect Dis Poverty 2014; 3:30. doi: 10.1186/2049-9957-3-30

22. Tchuenté LA, Shaw DJ, Polla L, Cioli D, Vercruysse J. Efficacy of praziquantel against Schistosoma haematobium infection in children. Am J Trop Med Hyg 2004; 71:778-82. doi: 10.4269/ ajtmh.2004.71.778.

23. Lui R, Dong HF, Guo Y, Zhao QP, Jiang MS. Efficacy of praziquantel and artemisinin derivatives for the treatment and prevention of human schistosomiasis: A systematic review and meta-analysis. Parasit Vectors 2011; 4:201. doi: 10.1186/17563305-4-201.

24. Garba A, Lamine MS, Barkiré N, Djibo A, Sofo B, Gouvras AN, et al. Efficacy and safety of two closely spaced doses of praziquantel against Schistosoma haematobium and S. mansoni and re-infection patterns in school-aged children in Niger. Acta Trop 2013; 128:334-44. doi: 10.1016/j.actatropica.2012.08.008.

25. Augusto G, Magnussen P, Kristensen TK, Appleton CC, Vennervald BJ. The influence of transmission season on parasitological cure rates and intensity of infection after praziquantel treatment of Schistosoma haematobium-infected schoolchildren in Mozambique. Parasitology 2009; 136:1771-9. doi: 10.1017/S0031182009006210.

26. Mekonnen A, Legesse M, Belay M, Tadesse K, Torben W, Teklemariam Z, et al. Efficacy of praziquantel against Schistosoma haematobium in Dulshatalo village, Western Ethiopia. BMC Res Notes 2013; 6:392. doi: 10.1186/1756-0500-6-392.

27. King $\mathrm{CH}$. Long-term outcomes of school-based treatment for control of urinary schistosomiasis: A review of experience in Coast Province, Kenya. Mem Inst Oswaldo Cruz 2006; 101:299-306. doi: 10.1590/S0074-02762006000900047.

28. Ahmed AM, Abbas H, Mansour FA, Gasim GI, Adam I. Schistosoma haematobium infections among schoolchildren in central Sudan one year after treatment with praziquantel. Parasit Vectors 2012; 5:108. doi: 10.1186/1756-3305-5-108. 